\title{
Factors Affecting Poverty in Indonesia: A Panel Data Approach
}

\author{
Nano PRAWOTO' ${ }^{\star}$, Agus Tri BASUKI ${ }^{2}$ \\ ${ }^{1}$ Faculty of Economic and Business, Universitas Muhammadiyah Yogyakarta, Indonesia. \\ Email: nanopra@umy.ac.id \\ ${ }^{2}$ Faculty of Economic and Business, Universitas Muhammadiyah Yogyakarta, Indonesia. \\ Email: agustribasuki@yahoo.com \\ ${ }^{*}$ Corresponding Author
}

\begin{abstract}
Received: 19.11.2021
Accepted: 22.12.2021

Published: 02.02.2022

DOI: 10.47750/QAS/23.186.20
\end{abstract}

\begin{abstract}
Poverty is a significant disease in economic development. Thus, the main objective of a country's economic development is to reduce the number of poor people by increasing gross regional domestic product, investment, regional spending, and infrastructure. The purpose of this study is to see and analyze the impact of an increase in gross regional domestic product, investment, regional spending, and infrastructure improvements on the number of poor people. This study uses panel data regression with path analysis. This method can explain the correlated variables by using a sequential model temporarily and identify the path of the cause of a particular variable to other variables that are influenced by it. Data sources come from the Central Bureau of Statistics and Bank Indonesia from 34 provinces in 2015-2019. The study results indicate that an increase in investment and regional spending indirectly affects the reduction of the number of poor people through an increase in the gross regional domestic product. Investment, exchange rates, road length, human development index, and regional spending affect economic growth. Regional expenditure and total population directly affect the number of poor people, while investment does not directly affect the number of poor people.
\end{abstract}

Keywords: Economic Growth, Number of Poor Population, Economic Development

\section{Introduction}

In 1990 Indonesia succeeded in reducing the number of poor people through development strategies, namely economic stability, economic growth, and economic equity (Trilogy of Development in the Old Order Regime). According to the World Bank, Indonesia had reduced the relative population from 40.08 percent in 1976 to 17.42 percent in 1987 . This success is mainly the development of the agricultural sector which has contributed significantly to poverty reduction in the agricultural sector, especially in rural areas. In addition, improving access to consumption of social services (education, health, and nutrition) is an important policy tool in the government's overall strategy to reduce and improve the population's welfare. During the reform period, the number of poor people in September 2020 was 27.55 million people (10.19 percent of the total population), an increase of 1.13 million people compared to March 2020 and an increase of 2.76 million people (0.97 percent) compared to September 2019 This increase occurred because of the pandemic that hit Indonesia, but also many countries in the world.

Poverty is not a condition of lack of a commodity or a problem of satisfaction with the commodity, but poverty is more likely a condition of people who are less able to maximize functions and take advantage of the commodity (Škare \& Družeta, 2016; Todaro \& Smith, 2012; Yang, 2017). Poverty is a multi-dimensional problem that includes political, social, economic, asset, and access issues (Azike \& Ngwu, 2021).
This results in poor people being excluded from the decisionmaking process that concerns themselves. Moreover, all the efforts they do not have access to, including adequate information to various resources needed to improve their standard of living properly.

The dimensions of poverty are interrelated with each other, either directly or indirectly. This means that progress or decline in one aspect can affect progress or decline in other aspects. Another aspect of poverty is that the poor are human beings, both individually and in groups. There are many terms in poverty, such as rural poverty and urban poverty. However, it does not mean that villages or cities are experiencing poverty, but the people or residents suffer. Thus, poverty can be observed as a condition of community members who have not participated in the process of change because they do not have the ability, both the ability to own production factors and adequate quality of production factors so that they do not benefit from the results of the development process. This nonparticipation in the development process can be caused because, naturally, they have not utilized their production factors and may occur unnaturally. Therefore, the problem of poverty is still relevant and essential to study and strive to overcome so that the goals of fair and equitable national development can be realized.

\section{Previous Studies}

Research on the effect of foreign investment on economic 
growth was conducted by Anetor (2020). The study results conclude that foreign direct investment has a significant and negative impact on economic growth in SSA countries. Research by Hossain and Hossain (2012) concludes that there is no co-integration between FDI and GDP in Bangladesh and India in the long and short term. However, there is cointegration between the two in the short and long term in Pakistan. On the other hand, the GC results show no causal relationship between GDP and FDI for Bangladesh, and a unidirectional relationship is found for Pakistan and India, which means that FDI causes an increase in economic output in Pakistan.

Research on the effect of exchange rates on economic growth was conducted by Akram and Rath (2017). This study concludes that an increase in exchange rate misalignment causes a decrease in economic growth and vice versa. In addition, positive misalignment (overvaluation) is detrimental to economic growth, and negative misalignment (undervaluation) encourages economic growth.

Research on the relationship between infrastructure and economic growth was carried out by Apurv and Uzma (2021) conclude that there is an insignificant relationship between infrastructure investment and development and economic growth in Brazil and South Africa. Investment and construction of energy and transport infrastructure are driving economic growth in Russia.

Research on the relationship between human development and economic growth was carried out by Reyes and Useche (2019) conclude that the Dominican Republic shows an inverse relationship between competitiveness and economic growth, while Jamaica and Venezuela show an inverse relationship between competitiveness and human development. At the individual country level, no statistically significant relationship between economic growth and human development was detected.

Research on the effect of government spending on economic growth was conducted by Amusa and Oyinlola (2019). The empirical findings show that aggregate spending has a negative effect in the short term and a positive effect in the long run on economic growth. While the research of Dudzevičiūtè, Šimelytè, and Liučvaitienè (2018) with the title Government expenditure and economic growth in the European Union countries. The results of his research provide new evidence on the impact of government spending on economic growth in European Union countries for the period 1994-2012. There is a positive relationship for some EU countries (Portugal and the United Kingdom). At the same time, there is a negative relationship for other countries (Austria, Finland, Italy, and Sweden) or even not significant (Belgium, France, Greece, Ireland, Ireland, Luxembourg, the Netherlands, and Spanish).

Pham and Riedel researched the relationship between economic growth and poverty (2019) concluded that economic growth was not significant for poverty alleviation in 2010-2016. In addition, the urbanization process, the increase in the number of workers, and the literacy rate make a positive contribution to the achievement of poverty alleviation. Lastly, population growth is also one reason that hinders the success of Vietnam's poverty alleviation process. Another study conducted by Sasmal and Sasmal (2016) examines the impact of public spending on economic growth and poverty alleviation in developing countries such as India. If poverty and inequality are high, governments can use distributive policies at the expense of long-term growth. Distributive policies and poverty alleviation measures failed to achieve success due to a lack of good governance, proper targeting, and problems in implementing the scheme. On the other hand, if public spending increases per capita income, it will help reduce poverty.

\section{Methods}

The regression model that will be used is path analysis with panel data. According to Retherford and Choe (1993), path analysis is a technique to analyze the causal relationship in multiple regression if the independent variable affects the dependent variable directly and indirectly. Meanwhile, panel data (Gujarati \& Porter, 1999) combines time-series data and cross-section data. Time series data is data from one object with several specific periods, while cross-section data is obtained from one or more research objects in the same period. So the use of path analysis with panel data has the following advantages: the ability to test the overall model and individual parameters, model several mediator variables, and estimate using equations that can see all possible causal relationships on all variables in the model.

The econometric model used is a panel data path analysis model. The Path Analysis Model that will be used in the regression equation is as follows:

PDRB $=\beta 0+\beta 1 I N V+\beta 2$ KURS + $\beta 3 P J+\beta 4 I P M+\beta 5 B D+$

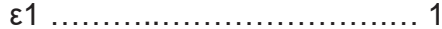

$\mathrm{POV}=\beta 0+\beta 6 \mathrm{PDRB}+\beta 7 \mathrm{INV}+\beta 8 \mathrm{BD}+\beta 9 \mathrm{POP}+\varepsilon 2$ .. 2

Then the regression equation is changed in the form of a logarithmic equation and the following equation is obtained:

Log PDRB $=\beta 0+\beta 1$ LogINV + $\beta 2$ LogKURS $+\beta 3$ LogPJ + $\beta 4 I P M+\beta 5 \log B D+\varepsilon 1 \ldots \ldots . .3$

$\log P O V=\beta 0+\beta 6 \log P D R B+\beta 7 \log I N V+\beta 8 \log B D+$ $\beta 9 \log P O P+\varepsilon 2 \ldots \ldots \ldots \ldots \ldots \ldots . \ldots$

Information:

PDRB

INV

KURS

PJ

IPM

BD

POV

POP

Bo

$\beta 1, \beta 2, \ldots \beta n$

$\varepsilon 1$

$\varepsilon 2$

Log

Gross Regional Domestic Product

Investment

Exchange rate

Road Length

Human Development Index

Regional Budget

Poverty (Number of Poor People)

Population (Total Population)

Constant

Coefficient

Error substructure 1

Error substructure 2 Logarithm

Panel data regression provides an alternative research model through 3 equations: Common Effect, Fixed Effect, and Random Effect. The Common Effect and Fixed Effect models use the Ordinary Least Squared (OLS) approach in their estimation technique, while the Random Effect uses Generalized Least Squares (GLS) as the estimation technique. The classical assumption test used in linear regression with the Ordinary Least Squared (OLS) approach includes linearity, autocorrelation, heteroscedasticity, multicollinearity, and normality tests. However, not all classical assumption tests have to be performed on every linear regression model using the OLS approach.

After forming the equation for path analysis, data is needed to support the equation. The type of data used in this research is quantitative data. Quantitative data is data in the form of numbers. The source used is secondary data. Secondary data is data obtained or collected by the agency researching existing sources. The Central Statistics Agency (BPS), Bank Indonesia, and the World Bank used the data sources. The data used is a combination of cross-section and time-series data taken from 34 provinces in Indonesia from 2015 to 2019. 


\section{GENERAL MANAGEMENT}

\section{Results and Discussion}

The first step is to translate Figure 1 of the path analysis model into a regression equation (eq1 and eq2)

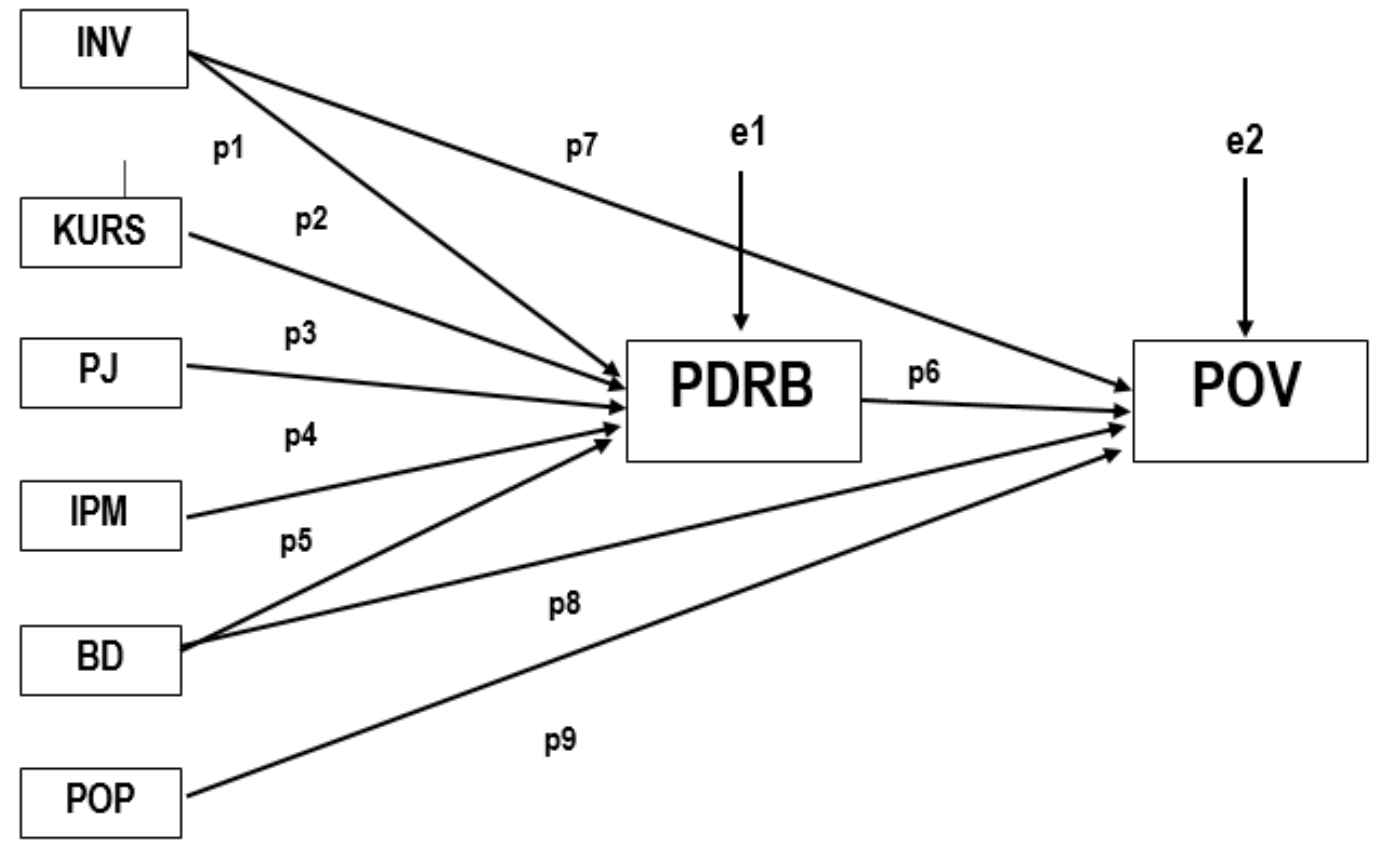

Figure 1: Path analysis model

Furthermore, from Figure 1, the regression equation can be derived as follows:

Log PDRB $=\beta 0+\beta 1$ LogINV + $\beta 2$ LogKURS $+\beta 3$ LogPJ $+\beta 4 I P M+\beta 5 \operatorname{LogBD}+\varepsilon 1 \ldots \ldots$ eq1

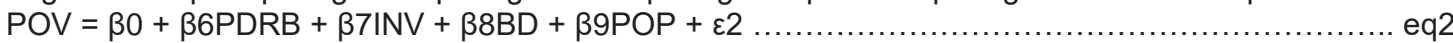

After the selected model is formed in the equation and passes the Classical Assumption test, the results of equation 1 can be displayed as follows:

\begin{tabular}{|l|l|l|l|l|}
\hline \multirow{2}{*}{ Variable } & \multicolumn{2}{l|l|}{ Fixed Effect Model } & \multicolumn{2}{l|}{ Random Effect Model } \\
\cline { 2 - 5 } & Coefficient & t-Statistic & Coefficient & t-Statistic \\
\hline LOG(INV) & 0.019447 & $2.264247^{* *}$ & 0.158305 & $6.038298^{* * *}$ \\
\hline LOG(PJ) & -0.032193 & -0.483389 & 0.350150 & $3.563790^{* * *}$ \\
\hline LOG(KURS) & 0.079739 & 0.683158 & -1.311313 & $-2.343840^{* *}$ \\
\hline IPM & 0.091834 & $15.41634^{* * *}$ & 0.058820 & $4.749958^{* * *}$ \\
\hline LOG(BD) & 0.247207 & $6.760178^{* * *}$ & 0.683645 & $8.552080^{* * *}$ \\
\hline C & 18.57177 & $14.40289^{* * *}$ & 16.38881 & $3.075411^{* * *}$ \\
\hline R-squared & 0.999194 & 0.718247 & \\
\hline F-statistic & 5511.612 & 83.61420 & \\
\hline Dependent Variable Log(PDRB) & & \\
\hline
\end{tabular}

Table 1: Results of pathway analysis regression equation for model 1

Note: ${ }^{* * *}$ significant $\alpha=1 \%{ }^{* *}$ significant $\alpha=5 \%{ }^{*}$ significant $\alpha=10 \%$

From the Hausman test results, it can be concluded that the best model is the Random Effect Model. The results of the regression equation model 1:

Log PDRB $=\beta 0+\beta 1$ LogINV + $\beta 2$ LogKURS + $\beta 3$ LogPJ + $\beta 4 I P M+\beta 5$ LogBD $+\varepsilon 1$ 


\section{GENERAL MANAGEMENT}

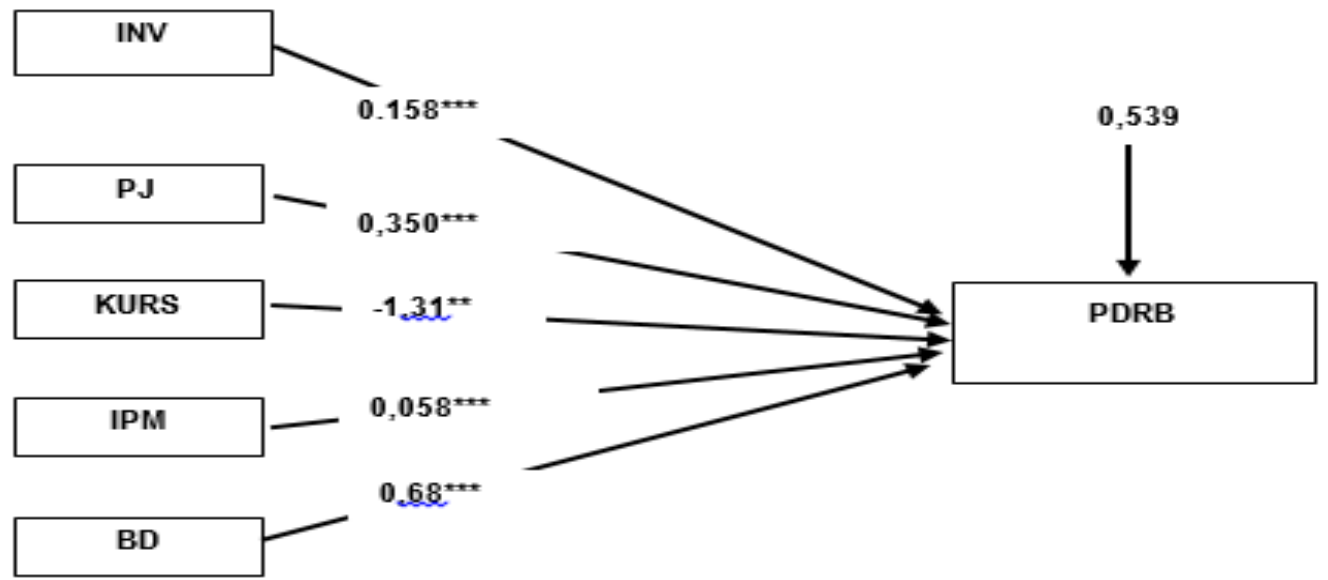

Figure 2: Regression results of equation 1

Note: The formula e1 can be searched with the formula ${ }^{e 1}={ }_{(1-R 2) 1 / 2}$

Note: ${ }^{* * *}$ significant $\alpha=1 \%{ }^{* *}$ significant $\alpha=5 \%$ * significant $\alpha=10 \%$

\begin{tabular}{|l|l|l|l|l|}
\hline & \multicolumn{2}{l|}{ Model Fixed Effect } & \multicolumn{2}{l|}{ Model Random Effect } \\
\hline Variable & Coefficient & t-Statistic & Coefficient & t-Statistic \\
\hline C & 0.106708 & 0.062619 & 5.656889 & $4.404678^{* * *}$ \\
\hline LOG(PDRB) & -0.549792 & $-6.280867^{* * *}$ & -0.060263 & $-2.350777^{* *}$ \\
\hline LOG(INV) & -0.084481 & $-1.860753^{*}$ & 0.003230 & 0.411923 \\
\hline LOG(BD) & 0.391414 & $4.607110^{* * *}$ & -0.215387 & $-6.383066^{* * *}$ \\
\hline LOG(POP) & 1.319310 & $19.62918^{* * *}$ & 1.020009 & $10.03198^{* * *}$ \\
\hline R-squared & 0.851899 & & 0.467822 & \\
\hline F-statistic & 115.7622 & & 36.26167 & \\
\hline Dependent Variable Log(POV) & & & \\
\hline
\end{tabular}

Table 2: Results of pathway analysis regression equations for model 2

Note: *** significant $\alpha=1 \%$ ** significant $\alpha=5 \%$ * significant $\alpha=10 \%$

From the Hausman test results, it can be concluded that the best model is the Random Effect Model. The results of the regression equation model 2:

$\mathrm{POV}=5.657-0.06 \mathrm{PDRB}+0.0032 \mathrm{INV}-0.215 \mathrm{BD}+1.02 \mathrm{POP}+\varepsilon 2$

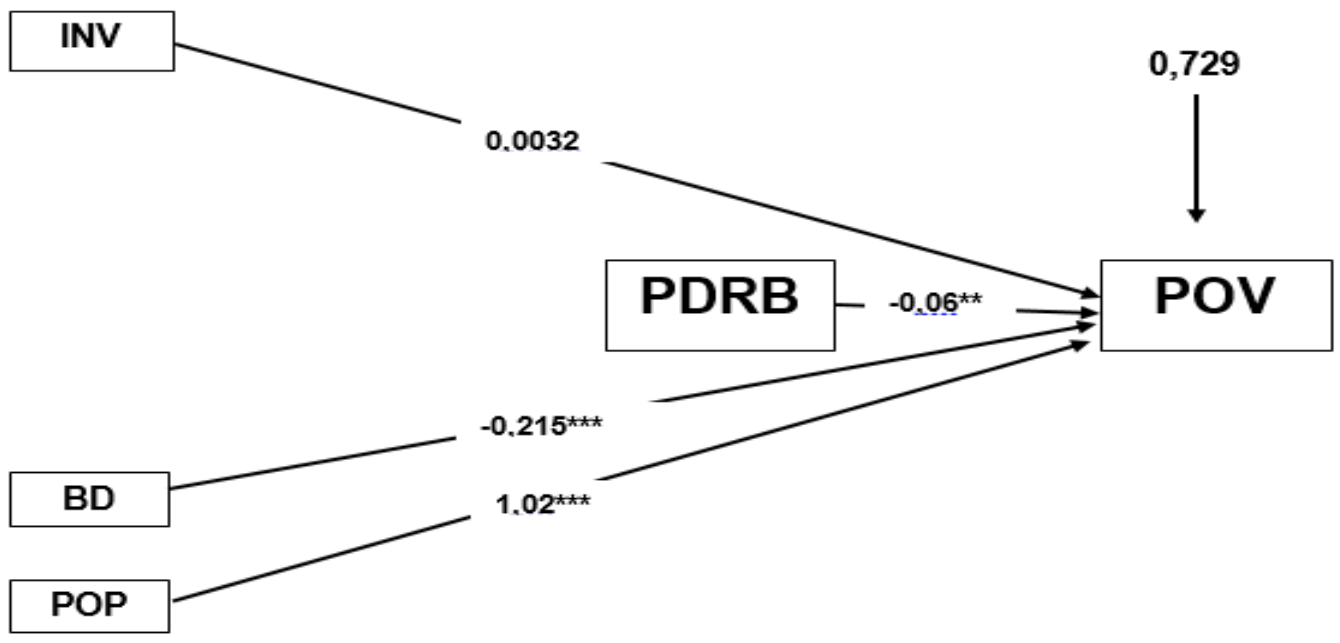

Figure 3: Regression results of equation 2

Note: The formula e1 can be searched with the formula ${ }^{e 1}={ }_{(1-R 2) 1 / 2}$

Note: ${ }^{* * *}$ significant $\alpha=1 \%{ }^{* *}$ significant $\alpha=5 \%{ }^{*}$ significant $\alpha=10 \%$ 


\section{GENERAL MANAGEMENT}

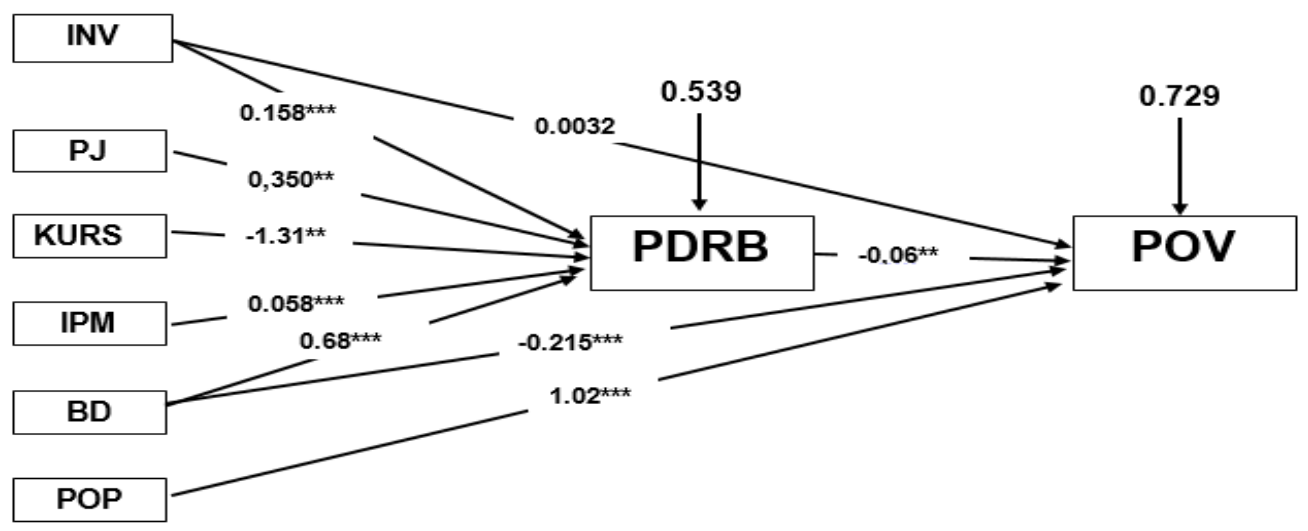

Note: *** significant $\alpha=1 \%{ }^{* *}$ significant $\alpha=5 \%$ * significant $\alpha=10 \%$

Figure 4: Regression results of equation 1 and 2

To see whether the independent variable indirectly affects the dependent variable, the Sobel test is needed. The Sobel test determines whether the relationship through a mediating variable is significantly capable of being a mediator in the relationship.

\begin{tabular}{|l|l|l|l|}
\hline Variable & Direct Effects (\%) & $\begin{array}{l}\text { Indirect Effects (\%) } \\
\text { (Through GDRP) }\end{array}$ & Total Effect (\%) \\
\hline Investment & 0.001 & $-0.0095^{\star *}$ & -0.0095 \\
\hline Long Way & & $-0.0211^{\star *}$ & -0.0211 \\
\hline Exchange Rate & & $0.0790^{* *}$ & 0.0790 \\
\hline HDI & $-0.0035^{\star *}$ & -0.35 \\
\hline $\begin{array}{l}\text { Local Government } \\
\text { Expenditure }\end{array}$ & $0.00464^{* * *}$ & $-0.00412^{* *}$ & 0.00052 \\
\hline GDRP & $0.0036^{* *}$ & & 0.0036 \\
\hline
\end{tabular}

Table 3: The direct and indirect effects of exogenous and endogenous variables on the poor Note: ${ }^{* * *}$ significant $\alpha=1 \%{ }^{* *}$ significant $\alpha=5 \%$ * significant $\alpha=10 \%$

The results showed that investment had no significant effect on the number of poor people. This result can be seen from the probability value of $t$ count $>=5 \%$. This shows that investment does not directly affect the number of poor people. The effect of investment on the number of poor people through the mediation of gross regional domestic product. Gross Regional Domestic Product mediates the effect of investment on the number of poor people in 34 provinces for the 20152019 period. The Sobel test pieces of evidence show the results of the statistical $z$ value of the mediation effect of -2.19 , which is greater than the $z$ table, which is 1.96 with a significance level of 0.05 . The direct effect of investment on the number of poor people is 0.001 . Meanwhile, the magnitude of the indirect effect of investment on the number of poor people through the gross regional domestic product is -0.0095 . To further ensure that the results of development can be enjoyed by the whole community so that poverty reduction can be made through improving social, economic, and cultural conditions and improving the welfare of the poor. The development strategy carried out by the government can be through progrowth, to increase and accelerate economic growth through efforts to attract investment, regional spending, exchange rates, and HDI; Pro-Poor (pro-poor), to increase the capacity and quality of the community so that they can contribute to development, expand access to basic services, and revitalize the agricultural, forestry, marine, and rural economic sectors.

The effect of the length of the road on the number of poor people through the mediation of gross regional domestic product. Gross Regional Domestic Product mediates the effect of Road Length on the number of poor people in 34 provinces for the 2015-2019 period. The Sobel test pieces of evidence show the results of the calculation of the statistical $z$ value of the mediation effect of -1.9623 , which is greater than the $z$ table, which is 1.96 with a significance level of 0.05 . The indirect effect of the length of the road on the number of poor people through the gross regional domestic product is -0.0211 . The effect of the exchange rate on the number of poor people through the mediation of gross regional domestic product.

Gross Regional Domestic Product mediates the effect of the exchange rate on the number of poor people in 34 provinces for the 2015-2019 period. The Sobel test pieces of evidence show the results of the calculation of the statistical $z$ value of the mediating effect of 2.32, which is greater than the $z$ table, which is 1.96 with a significance level of 0.05 . The magnitude of the indirect effect of the exchange rate on the number of poor people through the gross regional domestic product is 0.0790 . The impact of a decrease in the rupiah currency will directly reduce the price of export goods. A decrease in the price of goods will cause the value of goods exports to increase and lead to an increase in GDP, and the impact of an increase in GDP will cause an increase in national income per capita, which in turn will reduce the number of poor people.

The effect of HDI on the number of poor people through the mediation of gross regional domestic product. Gross Regional Domestic Product mediates the impact of HDI on the number of poor people in 34 provinces for the 2015-2019 period. The Sobel test pieces of evidence show the results of the statistical $z$ value of the mediation effect of -2.106 , which is greater than the $z$ table, which is 1.96 with a significance level of 0.05 . The magnitude of the indirect effect of HDI on the number of poor people through the gross regional domestic product is -0.0035 . The Effect of Gross Regional Domestic Product on the Number of Poor Populations. The results showed that the Gross 
Regional Domestic Product had a significant effect on the number of poor people. This result can be seen from the probability value of $t$ count $<=5 \%$. This shows that the Gross Regional Domestic Product directly affects the number of poor people. The magnitude of the direct influence of Gross Regional Domestic Product on the number of poor people is 0.0036 .

The Effect of Regional Expenditure on the Number of Poor Populations. The study results show that Regional Expenditures have a significant effect on the number of poor people. This result can be seen from the probability value of $t$ count $<=5 \%$. This shows that the Regional Expenditure directly affects the number of poor people. The effect of Regional Expenditure on the number of poor people through the mediation of gross regional domestic product mediates the effect of Regional Expenditure on the number of poor people in 34 provinces for the $2015-2019$ period. The Sobel test pieces of evidence shows the results of the calculation of the statistical $z$ value of the mediation effect of -2.2667 , which is greater than the $z$ table, which is 1.96 with a significance level of 0.05 . The direct effect of Regional Expenditure on the Number of Poor Population is 0.0464. Meanwhile, the magnitude of the indirect effect of investment on the number of poor people through the gross regional domestic product is 0.0412. Government policies through government spending directly have a positive influence on the number of poor people. This is because the bureaucracies experience an excess of low-level employees and experience a shortage of educated and highly skilled top-level employees. Most local governments lack managers who are able to make decisions independently. The main problem is domestic political instability, and power often changes hands to improve public welfare and efficiency will be subordinated to political loyalty. In addition, there is often a replacement of bureaucratic officials due to changes in power.

In essence, the GDRP concept has a number of weaknesses, one of which is that it does not provide a clear indication of how the national income is actually given to the community as a whole, and can even disguise the fact that the welfare conditions of the relatively poorest population have not improved. Many people are not aware of the fact that the GDRP calculation is only an exclusive calculation of income growth for the middle and upper-class groups. It is proven in this study that the GDRP actually encourages the growth of the number of poor people directly. An increase in GDP will actually increase the number of poor people. Economic growth can increase the number of poor people if it causes an unequal distribution of ownership of assets or production factors such as land and capital among the population in several provinces in Indonesia. The concentration of wealth in the hands of the economic and political elites allows increasing resources through education so that the economic elite can play a role more freely in the process of creating national products.

\section{Conclusion}

There are two conclusions obtained from the analysis: an increase in investment directly does not affect the number of poor people. This is because the poor do not have access, including adequate information, to various resources needed to improve their standard of living properly (Todaro \& Smith, 2012). This investment will indirectly affect the poor if the increase in investment will increase per capita income and is accompanied by an even distribution of economic development results. The direct impact of local government spending on the poor has a positive effect. This is due to the ineffectiveness of government programs in reducing the number of poor people.
Meanwhile, the indirect policy effect of government spending through increasing regional income can reduce the poor. The government can reduce the poor through the role of nongovernmental organizations in the design and implementation of poverty reduction programs.

An important policy in the context of alleviating poverty and improving income distribution is an effort to reduce control or ownership of wealth centered on the economic elite. Improving the distribution of wealth for the lower economic class can be achieved through the opportunity to obtain education and decent work. In addition, the central and local governments need to implement dynamic redistribution policies, namely the transfer of a portion of annual investment and savings to lowincome groups. The government's provision of goods and services to the poor through the procurement of projects is to improve public health facilities in rural areas and improve infrastructure in remote areas. The process of income redistribution can be carried out in several ways, including by applying taxes proportionally to their personal income and wealth. Taxes are expected to increase government revenues which are then used to improve various social assistance programs and improve welfare as well as the incomes of the lowest-income groups.

\section{References}

[1] Yang, L. (2017). The relationship between poverty and inequality: Concepts and measurement. Centre for Analysis of Social Exclusion, 2, 1-37.

[2] Yang, L. (2017). The relationship between poverty and inequality: Concepts and measurement. Centre for Analysis of Social Exclusion, 2, 1-37.

[3] Yang, L. (2017). The relationship between poverty and inequality: Concepts and measurement. Centre for Analysis of Social Exclusion, 2, 1-37.

[4] Yang, L. (2017). The relationship between poverty and inequality: Concepts and measurement. Centre for Analysis of Social Exclusion, 2, 1-37.

[5] Azike, L. C., \& Ngwu, J. C. (2021). Poverty and Economic Growth Nexus in Nigeria. ESUT JOURNAL OF SOCIAL SCIENCES, 6(2), 136-153.

[6] Yang, L. (2017). The relationship between poverty and inequality: Concepts and measurement. Centre for Analysis of Social Exclusion, 2, 1-37.

[7] Gujarati, D. N., \& Porter, D. C. (1999). Essentials of econometrics (Vol. 2). Singapore: Irwin/McGraw-Hill.

[8] Yang, L. (2017). The relationship between poverty and inequality: Concepts and measurement. Centre for Analysis of Social Exclusion, 2, 1-37.

[9] Yang, L. (2017). The relationship between poverty and inequality: Concepts and measurement. Centre for Analysis of Social Exclusion, 2, 1-37.

[10] Retherford, R. D., \& Choe, M. K. (1993). Path analysis. Statistical Methods for Causal Analysis, 93-99.

[11] Yang, L. (2017). The relationship between poverty and inequality: Concepts and measurement. Centre for Analysis of Social Exclusion, 2, 1-37.

[12] Yang, L. (2017). The relationship between poverty and inequality: Concepts and measurement. Centre for Analysis of Social Exclusion, 2, 1-37.

[13] Yang, L. (2017). The relationship between poverty and inequality: Concepts and measurement. Centre for Analysis of Social Exclusion, 2, 1-37.

[14] Todaro, M. P., \& Smith, S. C. (2012). Economic Development (Eleven Edition). United Kingdom: Pearson Education Limited.

[15] Yang, L. (2017). The relationship between poverty and inequality: Concepts and measurement. Centre for Analysis of Social Exclusion, 2, 1-37. 